Article

\title{
Effect of Culture Conditions on Viability of Mouse and Rat Embryos Developed in Vitro
}

\section{Elena Popova, Michael Bader * and Alexander Krivokharchenko}

Max-Delbrück Center for Molecular Medicine (MDC), Robert-Rössle-Str. 10, D-13125, Berlin-Buch, Germany; E-Mails: 1.popova@mdc-berlin.de (E.P.); a.krivokharchenko@mdc-berlin.de (A.K.)

* Author to whom correspondence should be addressed; E-Mail: mbader@ mdc-berlin.de; Tel.: +49309406 2193; Fax: +493094062110.

Received: 14 January 2011; in revised form: 11 February 2011 / Accepted: 29 March 2011 / Published: 1 April 2011

\begin{abstract}
Currently in vitro culture of mouse preimplantation embryos has become a very important technique to investigate different mechanisms of early embryogenesis. However, there is a big difference in the preimplantation development between mammalian species. Despite close relatedness to mice, in vitro cultivation of rat preimplantation embryos is still delicate and needs further investigation and optimizations. In this study we have compared the in vitro developmental potential of mouse and rat embryos cultured at different culture conditions in parallel experiments. Interestingly, mouse zygotes developed in vitro until blastocyst stage even in inadequate medium without any phosphates and with low osmolarity which was formulated especially for cultivation of rat embryos. Rat parthenotes and zygotes developed in M16 medium formulated for mouse embryos only till 2-cell stage and further development is blocked completely at this stage. Moreover, developmental ability of rat embryos in vitro was significantly lower in comparison with mouse even in special rat mR1ECM medium. Mouse and rat embryos at 2-cell stage obtained in vivo developed until blastocyst stages significantly more efficiently compared to zygotes. Culture of mouse zygotes in glass capillaries resulted in a significantly higher rate of morula and blastocyst development compared with dishes. The Well-of-the-Well system resulted in a significant improvement when compared with dishes for the culture of rat zygotes only until morula stage. Reduced oxygen tension increased the developmental rate of rat but not mouse zygotes until blastocyst stage. This study demonstrates that development of early preimplantation embryos is altered by different culture conditions and show strong differences even between two related species such as mice and rats.
\end{abstract}


Therefore, for understanding the fundamental mechanisms of early mammalian development it is very important to use embryos of various species.

Keywords: preimplantation in vitro culture; culture system; oxygen tension; mouse and rat embryos

\section{Introduction}

In vitro cultivation of mammalian ova is a very important tool to study early embryogenesis and environments in which the early embryo can undergo a number of divisions and form a blastocyst. The greatest success and considerable information concerning in vitro culture requirements for embryos of preimplantation stages have been reported for mouse embryos [1-3]. Later different in vitro culture systems have been developed for embryos for a variety of agricultural mammals including rabbit, sheep, cows and pigs [4-7]. Impressive results were also obtained with the in vitro manipulation of human embryos. The main finding was that there are great species-specific and stage dependent differences in sensitivity of embryos removed from the female reproductive tract to different in vitro culture compounds and conditions.

In spite of this, mouse preimplantation embryos are still the most popular model which is commonly used for investigation of mammalian early development in vitro. However, if we want to understand the fundamental mechanisms of preimplantation development we have to study other models in addition.

One of the most easily available and suitable mammalian species is rat. Notably, a lot of genetically characterized outbred and inbred rat strains have been generated and can be used for embryological studies. There are also other reasons for investigating early rat embryos in vitro since some very interesting peculiarities of rat preimplantation development in vivo and especially in vitro have been observed. As an intriguing example, a very special medium (mR1ECM) was developed for the culture of rat embryos from the 1-cell stage to the blastocysts [8]. This medium is significantly different from medium commonly used for in vitro culture of embryos of other mammalian species including human. Thus, mR1ECM unlike other media is absolutely phosphate-free. Moreover, even very small concentrations of inorganic phosphate ions completely blocked development of early stage rat embryos. Simultaneously, this medium has a very low osmotic pressure (240 versus 280-290 mosmol in conventional media) and increasing osmolarity inhibits development of early rat embryos.

Also the current situation in rat cloning is completely different compared to other mammalian species. All early attempts to generate cloned rats by transfer of nuclei from embryonic blastomeres have been unsuccessful $[9,10]$. Only recently we have reported the full-term development of rats after transfer of early cell cycle stage blastomere nuclei from 2-cell embryos into parthenogenetically pre-activated enucleated oocytes [11]. After a lot of unsuccessful attempts to obtain live offspring after somatic cell nuclear transfer in rat [12-16] one report about a cloned rat using somatic cells as karyoplasts has been published [17]. However, up to now, this study remained singular and more recent attempts were again unsuccessful $[18,19]$. 
Also, to our knowledge, there is the only one report available in the literature showing successful in vitro blastocyst development of cloned rat embryos [13]. In contrast, all other authors reported that somatic cell nuclear transfer (SCNT) rat embryos arrested in vitro at the 2-cell stage [15,16,18-20]. The reasons for this discrepancy are still not clear but are probably based on peculiarities of rat embryology and difficulties with the reproducibility of experimental conditions.

The aim of our work was to compare the effects of different culture media and culture systems on the development of early mouse and rat embryos in vitro.

\section{Results and Discussion}

\subsection{In Vitro Development of Mouse Parthenogenetically Activated Oocytes, Zygotes and 2-Cell Stage} Embryos in Different Culture Mediums

In our experiments we studied the developmental ability in vitro of mouse and rat embryos of different stages such as parthenogenetically activated oocytes, zygotes and 2-cell stages using in parallel two different culture media. We used culture medium (mR1ECM) which was established especially for in vitro culture of rat embryos from 1-cell stage to the blastocyst stage [8]. M16 medium was selected as the most commonly used conventional medium for culture of mouse embryos in vitro [21]. Parthenotes can be efficiently obtained in vitro with variety of mechanical, chemical, and electrical stimuli using oocytes of several species. Strontium is a very popular agent for parthenogenetic activation of mouse. In our previous experiments we also showed that rat parthenogenetically activated oocytes generated by strontium treatment successfully developed in vitro until blastocyst stage and were able to implant into the uterine wall after embryo transfer [22]. In these experiments we used established protocols for production of mouse and rat parthenotes and studied in vitro development until blastocyst stage in "rat" (mR1ECM) and "mouse" (M16) media using 4-well culture dishes.

As shown in Table 1, the rate of first cleavage of rat and mouse oocytes was not affected by the medium. However, the rate of development of activated mouse oocytes to the morula and blastocyst stages in mR1ECM (80.9 and 66.2\%) was significantly lower compared with M16 medium (90.3 and $81.9 \%)$. Cells were counted in mouse blastocyst developed from activated oocytes in both groups. The number of cells in blastocysts developed in M16 medium was significantly higher $(31.5 \pm 1.9(\mathrm{n}=11))$ than in blastocysts cultured in mR1ECM $(23.6 \pm 2.1(\mathrm{n}=9))(\mathrm{P}<0.05)$. Rat parthenotes developed successfully until 2-cell stage after overnight culture in M16 medium (83.6\%; 112/134) but none of them could develop further. However, 2-cell embryos transferred into mR1ECM developed until blastocyst stages $(19.4 \%)$ but at lower rate than both groups of mouse parthenotes (66.2-81.9\%) $(\mathrm{P}<0.05)$. The number of cells in blastocysts from rat parthenogenetic blastocysts was significantly lower $(14.8 \pm 1.6(\mathrm{n}=5))$ compared to all other groups regardless of the medium used $(\mathrm{P}<0.05)$.

We also assayed the ability of mouse and rat zygotes to develop in vitro using the same culture media and 4-well culture dishes which were previously described. As shown in Table 2, the rates of development to two-cell stage in mice did not depend on the medium (88.8-91.6\%). However, the development to the morula and blastocyst stages and the mean number of cells per blastocyst were significantly lower for mouse zygotes cultured in mR1ECM compared to M16 medium $(\mathrm{P}<0.05)$. 
Table 1. Effect of culture medium on in vitro development of mouse and rat parthenogenetically activated oocytes.

\begin{tabular}{|c|c|c|c|c|c|}
\hline \multirow{2}{*}{$\begin{array}{l}\text { Medium } \\
\text { and } \\
\text { Species }\end{array}$} & \multirow{2}{*}{$\begin{array}{c}\text { No. of } \\
\text { Activated } \\
\text { Oocytes } \\
\text { Cultured }\end{array}$} & \multicolumn{3}{|c|}{ No. of Parthenotes (\%) } & \multirow{2}{*}{$\begin{array}{l}\text { Cell Number in } \\
\text { Blastocysts } \\
(\text { mean } \pm \text { SE) }\end{array}$} \\
\hline & & 2-cells & Morula & Blastocyst & \\
\hline $\begin{array}{c}\text { mR1ECM } \\
\text { mouse }\end{array}$ & 136 & $131 / 136(96.3)$ & $110 / 136(80.9)^{*}$ & $90 / 136(66.2) *$ & $23.6 \pm 2.1(n=9)+$ \\
\hline $\begin{array}{l}\text { M16- } \\
\text { mR1ECM } \\
\text { rat }\end{array}$ & 134 & $112 / 134(83.6)$ & $55 / 134(41.0)^{* *}$ & $26 / 134(19.4)^{* *}$ & $14.8 \pm 1.6(\mathrm{n}=5) * *$ \\
\hline M16 mouse & 72 & $72 / 72(100)$ & $65 / 72(90.3)$ & $59 / 72(81.9)$ & $31.5 \pm 1.9(n=11)$ \\
\hline M16 rat & 134 & $112 / 134(83.6)$ & $0 / 134(0)$ & $0 / 134(0)$ & - \\
\hline
\end{tabular}

Values with different superscripts in the same column are significantly different.

*: Significantly different from M16 ( $\mathrm{P}<0.05)$; +: Significantly different from M16 $(\mathrm{P}<0.05)$.

**: Significantly different from other groups $(\mathrm{P}<0.001)$.

Table 2. Influence of culture medium on in vitro development of mouse and rat zygotes.

\begin{tabular}{|c|c|c|c|c|c|}
\hline \multirow{2}{*}{$\begin{array}{l}\text { Medium } \\
\text { and } \\
\text { Species }\end{array}$} & \multirow{2}{*}{$\begin{array}{c}\text { No. of } \\
\text { Zygotes } \\
\text { Cultured }\end{array}$} & \multicolumn{3}{|c|}{ No. of Embryos Developed into, (\%) } & \multirow{2}{*}{$\begin{array}{l}\text { Cell Number in } \\
\text { Blastocysts } \\
\text { (mean } \pm \text { SE) }\end{array}$} \\
\hline & & 2-cells & Morula & Blastocyst & \\
\hline $\begin{array}{c}\text { mR1ECM } \\
\text { mouse }\end{array}$ & 152 & $135 / 152(88.8)$ & $115 / 152(75.7)^{*}$ & $99 / 152(65.1)^{*}$ & $37.8 \pm 1.7(\mathrm{n}=18)^{*}$ \\
\hline $\begin{array}{c}\text { M16- } \\
\text { mR1ECM } \\
\text { rat } \\
\end{array}$ & 150 & $141 / 150(94.0)$ & $90 / 150(60.0)^{* *}$ & $49 / 150(32.7)^{* *}$ & $19.5 \pm 1.3(\mathrm{n}=22)^{* *}$ \\
\hline $\begin{array}{c}\text { M16 } \\
\text { mouse }\end{array}$ & 167 & $153 / 167(91.6)$ & $140 / 167(83.8)$ & $126 / 167(75.4)$ & $45.0 \pm 3.1(n=21)$ \\
\hline $\begin{array}{c}\text { M16 } \\
\text { rat }\end{array}$ & 118 & 112/118(94.9) & $0 / 118(0)$ & $0 / 118(0)$ & - \\
\hline
\end{tabular}

Values with different superscripts in the same column are significantly different.

*: Significantly different from M16 group $(\mathrm{P}<0.05)$; **: Significantly different from other groups $(\mathrm{P}<0.01)$.

Rat zygotes developed efficiently in M16 medium until 2-cell stage (94.9\%; 112/118) without any differences compared to mouse zygotes $(91.6 \%$; 153/167). However, all embryos completely blocked at this stage like the parthenotes. When rat 2-cell stage embryos, after overnight culture in M16, were transferred into mR1ECM, they developed until morula and blastocyst stages (60 and 32.7\%) but at significantly lower rate than the two mouse groups $(75.7$ and $65.1 \%)(\mathrm{P}<0.01)$. The number of cells in rat blastocysts developed in vitro was almost half $(19.5 \pm 1.3(\mathrm{n}=22)$ that of the mouse embryos regardless of the culture medium used $(37.8 \pm 1.7(\mathrm{n}=18)$ for mR1ECM or $45.0 \pm 3.1(\mathrm{n}=21)$ for M16).

We also recovered from mouse and rat females 2-cell stage embryos and cultivated them in vitro in mR1ECM and M16 media until hatched blastocysts. There was no difference in the capability of in vivo produced mouse 2-cell stage embryos to reach late blastocyst stage in vitro in both tested media 
(93.6-96.2\%) (Table 3). However, we found dramatically lower rates of blastocyst hatching in mR1ECM medium -20.2 vs. 84.6 in M16. In vitro development of rat 2-cell stage embryos to the blastocyst stage was significantly less efficient than in mice. Only a few blastocysts (9.6\%) started and none of them completed hatching from zona pellucida.

Table 3. In vitro development of mouse and rat 2-cell stage embryos in various mediums.

\begin{tabular}{|c|c|c|c|c|}
\hline \multirow{2}{*}{$\begin{array}{c}\text { Medium and } \\
\text { Species }\end{array}$} & $\begin{array}{c}\text { No. of } \\
\text { 2-Cells } \\
\text { Cultured }\end{array}$ & Blastocyst & Hatching Blastocyst & Hatched Blastocyst \\
\cline { 3 - 5 } & 94 & $88 / 94(93.6)$ & $18 / 94(20.2)$ & $2 / 94(2.1)$ \\
\hline $\begin{array}{c}\text { mR1ECM } \\
\text { mouse }\end{array}$ & 52 & $36 / 52(69.2)^{*}$ & $5 / 52(9.6)$ & $0 / 52(0)$ \\
\hline mR1ECM rat & 52 & $50 / 52(96.2)$ & $44 / 52(84.6) * *$ & $33 / 52(63.5)^{* *}$ \\
\hline M16mouse & 44 & $0 / 44(0)$ & 0 & 0 \\
\hline M16 rat & 44 & & 0 \\
\hline
\end{tabular}

Values with different superscripts in the same column are significantly different.

*: Significantly different from other groups $(\mathrm{P}<0.05)$; **: Significantly different from all other groups $(\mathrm{P}<0.001)$.

A lot of manipulations with rat embryos were limited for a long time by problems with the in vitro cultivation of preimplantation embryos in this species. The reasons for the developmental block of rat embryos cultured in vitro in M16 medium have been discussed many years ago. Kishi et al. reported the development of zygotes from Wistar rats to blastocysts in vitro in HECM-1 medium with rates of 10-20\% depending on oxygen concentrations [24]. However, Ouhibi et al. could not obtain blastocysts from Wistar zygotes and only 5\% of one-cell embryos from CD rats developed to blastocysts in HECM-1 medium [25]. In contrast, Matsumoto and Sugawara reported the development of $60 \%$ blastocysts from zygotes and more than $90 \%$ blastocysts from two-cell embryos using Wistar rats and HECM-1 medium [26]. The best rate was reported by Miyoshi et al. [26,27], who used one-cell rat embryos and achieved to get $60-90 \%$ blastocysts in a modified R1ECM medium. That is why this medium has become most popular and useful for successful cultivation of rat preimplantation embryos until blastocyst stage in vitro.

Interestingly, mouse parthenogenetic embryos, zygotes and 2-cell stage, could develop until blastocyst stage even in inadequate rat mR1ECM medium but at a lower rate compared with M16. In vitro culture of mouse 2-cell stage embryos in M16 resulted in a higher hatching rate probably because of the presence of BSA and other important components in this medium. Rat parthenotes and zygotes developed in M16 medium only until 2-cell stage and then development was completely blocked. Moreover, developmental ability of rat embryos in vitro was significantly lower in comparison with mouse even in the special rat medium, mR1ECM. So far in vitro culture of rat preimplantation embryos until blastocyst stage in established culture conditions remains still suboptimal and needs further optimizations.

\subsection{In Vitro Development of Mouse and Rat Embryos in Different Culture Systems}

There are a lot of factors affecting the efficiency of in vitro development of embryos in various mammalian species. One of the most important is embryo density (number of embryos per volume of 
medium) during cultivation, influencing the embryo interaction with soluble factors. The culture medium may dilute some important autocrine/paracrine factors effecting the viability and embryo developmental performance in vitro [28-30]. Various in vitro culture systems for preimplantation mammalian embryos have been established and described in the literature [3,31].

In our experiments, with the aim of improving in vitro development of rat embryos until blastocyst stage and to compare the developmental ability of mouse and rat embryos, zygotes and 2-cells of both species were cultured in vitro until blastocyst stage using three different culture systems.

Nunc 4-well dishes with $0.7 \mathrm{~mL}$ culture medium and 10 to 20 embryos per well is one of the most popular and conventional in vitro culture system for embryos of different mammalian species. We have previously also used this system successfully for the cultivation of mouse and rat embryos after different micromanipulations [11,22,32-34]. Glass capillaries with 10-50 $\mu 1$ of culture medium and 10 embryos per capillaries have been described for in vitro culture of mammalian embryos by Brinster many years ago [3]. This culture system was optimized and used to study the development of mouse embryos in vitro in a protein-free medium depending on the number of embryos in a small volume of medium [30]. The Well-of-the-Well or WOW culture system is another approach in which embryos are cultured in small indentations or microwells formed on the bottom of a plastic culture dish. This system was first developed for the individual culture of zona-free embryos [35,36]. Moreover, it was also shown to be efficient for culturing of zona-intact cattle embryos [35]. In our experiments we cultured mouse and rat zygotes and 2-cell stage embryos individually, one in each microwell.

Table 4 shows the in vitro development of rat embryos using three different culture systems. The cleavage rate of zygotes was the same for all culture systems tested. However, culture of zygotes in the WOW system resulted in a significantly improved development until morula stage $(70.4 \% ; 50 / 71)$ compared with zygotes cultured in Nunc dishes $(53.0 \%$; 44/83) (P < 0.05). However, we did not find any significant differences in blastocyst development for these groups of zygotes. Two-cell stage rat embryos developed in vitro without any differences between three studied culture systems.

Table 4. In vitro development of rat embryos using various culture systems.

\begin{tabular}{|c|c|c|c|c|c|}
\hline \multirow{2}{*}{$\begin{array}{c}\text { Culture } \\
\text { System }\end{array}$} & \multirow{2}{*}{$\begin{array}{c}\text { Stage of } \\
\text { Embryos }\end{array}$} & $\begin{array}{c}\text { No. of } \\
\text { Embryos } \\
\text { Cultured }\end{array}$ & \multicolumn{2}{|c|}{ No. of Embryos Developed into, (\%) } \\
\cline { 4 - 7 } & 2-cells & Morula & Blastocyst \\
\hline \multirow{2}{*}{$\begin{array}{c}\text { Nunc } \\
\text { dishes }\end{array}$} & Zygotes & 83 & $79 / 83(95.2)$ & $44 / 83(53.0)$ & $24 / 83(28.9)$ \\
\cline { 2 - 6 } & $\begin{array}{c}\text { 2-cells } \\
\text { embryos }\end{array}$ & 74 & 74 & $62 / 74(83.8)$ & $53 / 74(71.6)$ \\
\hline \multirow{2}{*}{$\begin{array}{c}\text { Glass } \\
\text { capillaries }\end{array}$} & Zygotes & 54 & $50 / 54(92.6)$ & $31 / 54(57.4)$ & $14 / 54(25.9)$ \\
\cline { 2 - 6 } & $\begin{array}{c}2-\text {-cells } \\
\text { embryos }\end{array}$ & 48 & 48 & $39 / 48(81.3)$ & $30 / 48(62.5)$ \\
\hline \multirow{2}{*}{ WOW } & Zygotes & 71 & $65 / 71(91.5)$ & $50 / 71(70.4) *$ & $25 / 71(35.2)$ \\
\cline { 2 - 6 } & $\begin{array}{c}2-c e l l s \\
\text { embryos }\end{array}$ & 52 & 52 & $45 / 52(86.5)$ & $32 / 52(61.5)$ \\
\hline
\end{tabular}

Values with different superscripts in the same column are significantly different.*: Significantly different from zygotes cultured in Nunc dishes $(\mathrm{P}<0.05)$. 
Table 5 presents the results for the in vitro development of mouse embryos in different culture systems. The rates of cleavage of mouse zygotes were the same in all groups regardless of the culture system. However, culture of zygotes in glass capillaries resulted in a significantly more efficient development until morula and blastocyst stage (92.5 and 85.0\%) compared with Nunc dishes (79.9 and 74.5\%) ( $\mathrm{P}<0.05)$. Two-cell mouse embryos developed equally until morula and blastocyst stage in vitro.

Table 5. In vitro development of mouse embryos using various culture systems.

\begin{tabular}{|c|c|c|c|c|c|}
\hline \multirow{2}{*}{$\begin{array}{c}\text { Culture } \\
\text { System }\end{array}$} & \multirow{2}{*}{$\begin{array}{c}\text { Stage of } \\
\text { Embryos }\end{array}$} & $\begin{array}{c}\text { No. of } \\
\text { Embryos } \\
\text { Cultured }\end{array}$ & \multicolumn{2}{|c|}{ No. of Embryos Developed into, (\%) } \\
\cline { 4 - 6 } & 2-Cells & Morula & Blastocyst \\
\hline \multirow{2}{*}{$\begin{array}{c}\text { Nunc } \\
\text { dishes }\end{array}$} & $\begin{array}{c}\text { Zygotes } \\
\text { embryos }\end{array}$ & 110 & $106 / 110(96.4)$ & $87 / 110(79.9)$ & $82 / 110(74.5)$ \\
\cline { 4 - 6 } & Zygotes & 80 & $80 / 80(100)$ & $74 / 80(92.5)^{*}$ & $68 / 80(85.0)^{*}$ \\
\hline \multirow{2}{*}{$\begin{array}{c}\text { Glass } \\
\text { capillaries }\end{array}$} & $\begin{array}{c}2 \text {-cells } \\
\text { embryos }\end{array}$ & 50 & 50 & $49 / 50(98.0)$ & $46 / 50(92.0)$ \\
\hline \multirow{2}{*}{ WOW } & Zygotes & 78 & $76 / 78(97.4)$ & $69 / 78(88.5)$ & $61 / 78(78.2)$ \\
\cline { 4 - 6 } & $\begin{array}{c}2-c e l l s \\
\text { embryos }\end{array}$ & 40 & 40 & $40 / 40(100)$ & $40 / 40(100)$ \\
\hline
\end{tabular}

Values with different superscripts in the same column are significantly different. *: Significantly different from zygotes cultured in Nunc dishes $(\mathrm{P}<0.05)$.

It was also reported that culture in glass capillaries is an efficient method of culturing of zona-free rabbit embryos. The authors compared three different culture systems and concluded that this method allows for the regular development of a high percentage of early rabbit embryo stages and for the simplification of some of the experimental procedures used in embryological research [37]. The WOW system resulted in significant improvement when compared to the drop-under-oil culture of in vitro-matured and parthenogenetically activated porcine oocytes, in vivo derived mouse zygotes and in vitro-fertilized human zygotes [38].

Taken together, the WOW system resulted in a significant improvement when comparing the Nunc dishes for culture of rat zygotes only until morula stage. However, the percentage of zygotes which developed until blastocysts was not improved. In mice we found a positive effect on culture until blastocyst stage in glass capillaries compared with Nunc dishes. Probably, rat embryos do not produce enough autocrine or paracrine factors in vitro unlike embryos of other mammalian species. Therefore, it would be very interesting to study the in vivo viability of rat embryos cultured in vitro at different culture conditions after transfer to foster mothers.

\subsection{In Vitro Development of Mouse and Rat Embryos under 5\% or 20\% Oxygen}

Several studies have shown that mammalian embryos develop better at reduced oxygen tension $[39,40]$. Higher concentration of oxygen was found to be toxic, probably due to the formation of oxygen radicals which induce detrimental effect not only on in vitro development but also on embryo metabolism [41] and gene expression [42]. However, to our knowledge, only one study has been 
performed about the possible effects of oxygen tension on rat embryos [43] and little is known about possible species-specific differences in sensitivity to oxygen tension of mouse and rat embryos.

In this study we have compared the in vitro development of mouse and rat embryos at atmospheric oxygen concentration of $20 \%$ and reduced oxygen concentration of 5\% using 4-well culture dishes in parallel experiments (Table 6). In these experiments we used conventional in vitro culture conditions established for rat and mouse embryos. Thus, mouse embryos were cultured from zygote until blastocyst stage in M16 medium, whereas rat zygotes were cultured overnight in M16 and then transferred into mR1ECM medium in Nunc 4-well culture dishes. There were no differences in blastocyst development for mouse embryos cultured below $5 \% \mathrm{O}_{2}$ or under atmospheric oxygen. However, the proportion of rat embryos developed to the blastocyst stage was significantly higher at reduced oxygen tension.

Table 6. Effects of oxygen concentration on the in vitro developmental ability in rat and mouse zygotes.

\begin{tabular}{|c|c|c|c|}
\hline \multirow{2}{*}{ Species } & Oxygen Tension & $\begin{array}{c}\text { No. of Embryos } \\
\text { Cultured }\end{array}$ & $\begin{array}{c}\text { No. of Embryos } \\
\text { Developed into } \\
\text { Blastocysts, (\%) }\end{array}$ \\
\hline \multirow{2}{*}{ Mouse (M16) } & $20 \%$ & 36 & $28 / 36(77.8)$ \\
\cline { 2 - 4 } Rat (M16- \\
mR1ECM) & $5 \%$ & 35 & $27 / 35(77.1)$ \\
\cline { 2 - 4 } & $20 \%$ & 89 & $25 / 89(28.1)^{*}$ \\
\hline
\end{tabular}

Values with different superscripts in the same column are significantly different.

*: Significantly different from all other groups $(\mathrm{P}<0.05)$.

These data are comparable with results published quite recently showing that reduction of oxygen tension enhanced development of rat 2-cell embryos to blastocysts in Wistar rats [43]. It would be very interesting to study embryos developed at different oxygen concentrations in more detail including the estimation of the number of cells in the inner cell mass and trophectoderm and of gene expression analysis. Further studies are warranted to estimate the in vivo developmental capacities of rat embryos cultured at reduced oxygen tension in vitro.

\section{Experimental Section}

\subsection{Animals}

Female C57BL/6N mice (23-25 days old) were obtained from Charles River (Sulzfeld, Germany). Female Sprague-Dawley-Hannover (SD-Hann) outbred rats (26-day-old) were obtained from a commercial animal breeder (Janvier, France). All mice and rats were kept at a temperature of $21+28{ }^{\circ} \mathrm{C}$ in a $12 \mathrm{~h} \mathrm{light/dark} \mathrm{cycle} \mathrm{(lights} \mathrm{on} 6.00$ a.m. -6.00 p.m.) with a humidity of $65+5 \%$. All experimental protocols were performed in accordance with the guidelines for the humane use of laboratory animals by the Max-Delbruck Center for Molecular Medicine and were approved by the local Ethics Committee. 


\subsection{Mouse and Rat Embryo Collection}

Immature mouse and rat females were induced to superovulate by intraperitoneal injection of gonadotrophins: 5 IU for mice or 15 IU pregnant mare's serum gonadotrophin for rats (Intervet, Unterschleißheim, Germany) followed $45-50$ h later by 5 IU for mice or 30 IU hCG (Intervet) for rats $[34,44]$. Superovulated females were sacrificed by cervical dislocation. Ovulated oocytes were collected 16-18 $\mathrm{h}$ after the hCG injection. To obtain embryos superovulated females were mated overnight with males of the same strain on the afternoon of Day 0. The criterion for mating was the presence of a vaginal plug on the following morning (Day 1 of pregnancy). Superovulated females were sacrificed at 12 p.m. -2 p.m. on Day 1 to collect zygotes. The oocytes and zygotes were recovered from the excised oviducts into M2 medium (Sigma) containing 0.1\% (w/v) hyaluronidase (Sigma) to remove cumulus cells. Mouse and rat in vivo produced 2-cells were recovered from the excised oviducts 45-48 hrs after hCG. Then, the ova were washed in M2 medium and used for manipulations.

\subsection{Parthenogenetic Activation of Oocytes}

Parthenogenetic activation of mouse and rat oocytes by strontium treatment was performed as described previously [22,34]. The oocytes were incubated for $30 \mathrm{~min}$ in $\mathrm{Ca}^{2+}$ and $\mathrm{Mg}^{2+}$-free $\mathrm{M} 16$ medium containing $2 \mathrm{mM} \mathrm{Sr}{ }^{2+}$ at $37{ }^{\circ} \mathrm{C}$ in a $\mathrm{CO}_{2}$ incubator. To obtain diploid parthenogenetic embryos, oocytes from all experimental groups were cultured $7-8 \mathrm{~h}$ in the presence of $5 \mathrm{mg} / \mathrm{mL}$ cytochalasin B (Sigma). The efficiency of pronuclear formation was analyzed 10-12 h after treatment. The oocytes were observed under an inverted microscope with Hoffmann optics. Those oocytes that formed visible pronuclei were recorded as activated.

\subsection{Embryo Culture}

For in vitro development rat and mouse embryos were cultured under $5 \% \mathrm{CO}_{2}$ in air at $37{ }^{\circ} \mathrm{C}$ in mR1ECM medium [27] and M16 (Sigma) [34]. To compare the development until blastocyst stage, rat embryos but not mouse embryos were overnight cultured in M16 medium and then transferred into mR1ECM. Previously, the culture medium was equilibrated with the gas phase and temperature in a $\mathrm{CO}_{2}$ incubator for 2-3 h. To study the possible effect of the culture system on in vitro development the embryos were transferred into three different culture systems: 10-20 embryos into $700 \mu \mathrm{L}$ of the medium in 4-well culture dishes (Nunc) [22]; 10 embryos into $25 \mu \mathrm{L}$ of the medium in glass microcapillaries under paraffin oil [30]; single embryos in small wells with approximately $250-\mu \mathrm{m}$ depth formed in 4-well dishes by melting the bottom with heated steel rods-Well of the Well (WOW) system [35].

Ova showing compaction and blastocoele cavity formation were classified as morulae and blastocysts, respectively. Blastocysts were classified as hatching when they were leaving zona pellucida and hatched when have completely left from zona pellucida. To study the possible effects of oxygen tension on in vitro development, mouse embryos were cultured in M16 medium and rat embryos were cultured overnight in M16 and then transferred into mR1ECM. Atmospheric oxygen concentration of $20 \%$ and reduced oxygen concentration of $5 \%$ was compared in parallel experiments. 


\subsection{Estimation of Embryo Cell Number}

Cultivated embryos were assessed for cell number at the blastocyst stage using modified air-drying technique [45]. Briefly, embryos were exposed to a hypotonic solution consisting of $25 \%$ culture medium and $75 \%$ deionised water for 40-50 min. Cells were spread and fixed using a 1:3 mixture of glacial acetic acid and methanol. Preparations were stained with Giemsa [32].

\subsection{Statistical Analysis}

The z-test was used to determine the significance of proportions and was calculated using the online resource http://www.dimensionresearch.com/resources/calculators/ztest.html. For comparison among three groups or more, data were evaluated by one-way analysis of variance (ANOVA) followed by multiple comparisons. The two-tailed Student's t-test was used to test for differences of means. A value of $\mathrm{p}<0.05$ was chosen as an indication of statistical significance.

\section{Conclusions}

Our results demonstrated that early preimplantation mouse embryos are very resistant to culture conditions and can not be a representative model for the effects of these conditions on in vitro mammalian development in general. On the other hand, early preimplantation rat embryos have marked peculiarities in their in vitro development. It would be very interesting and important to study subsequent development in vivo of rat embryos cultured in vitro at different culture conditions.

We propose that the metabolism of rat embryos and their gene expression profile is different from embryos of mouse and probably also of other mammals. These differences may contribute to the extraordinary difficulties researchers have faced when trying to clone rats.

Therefore, to understand the fundamental mechanisms of early mammalian development and genome reprogramming, it is not enough to investigate only mouse embryos. It is very important to also use embryos of other species. Hence, available genetically defined pre-implantation rat embryos can be one of the best additional and suitable models for various embryological experiments.

\section{Acknowledgements}

We would like to thank Cathrin Gerhard for skilful technical assistance. We acknowledge Annegret Dahlke, Kerstin Voigt and Monique Bergemann for animal care.

\section{Funding}

Supported by a grant of the European Union (EURATRANS).

\section{References and Notes}

1. Brinster, R.L. A method for in vitro cultivation of mouse ova from two-cell to blastocyst. Exp. Cell. Res. 1963, 32, 205-208.

2. Brinster, R.L. Studies on the development of mouse embryos in vitro. I. The effect of osmolarity and hydrogen ion concentration. J. Exp. Zool. 1965, 158, 49-57. 
3. Brinster, R.L. In vitro culture of mammalian embryos. J. Anim. Sci. 1968, 27, 1-14.

4. Dattena, M.; Mara, L.; Bin, T.A.A.; Cappai, P. Lambing rate using vitrified blastocysts is improved by culture with BSA and hyaluronan. Mol. Reprod. Dev. 2007, 74, 42-47.

5. Rizos, D.; Clemente, M.; Bermejo-Alvarez, P.; de La Fuente, J.; Lonergan, P.; Gutiérrez-Adán, A. Consequences of in vitro culture conditions on embryo development and quality. Reprod. Domest. Anim. 2008, 43, 44-50.

6. Lonergan, P.; Fair, T. In vitro-produced bovine embryos: dealing with the warts. Theriogenology 2008, 69, 17-22.

7. Vajta, G.; Rienzi, L.; Cobo, A.; Yovich, J. Embryo culture: can we perform better than nature? Reprod. Biomed. Online 2010, 20, 453-469.

8. Miyoshi, K.; Abeydeera, L.R.; Okuda, K.; Niwa, K. Effects of osmolarity and amino acids in a chemically defined medium on development of rat one-cell embryos. J. Reprod. Fertil. 1995, 103, 27-32.

9. Kono, T.; Shioda, Y.; Tsunoda, Y. Nuclear transplantation of rat embryos. J. Exp. Zool. 1988, 248, 303-305.

10. Shinozawa, T.; Mizutani, E.; Tomioka. I.; Kawahara, M.; Sasada, H.; Matsumoto, H.; Sato, E. Differential effect of recipient cytoplasm for microtubule organization and preimplantation development in rat reconstituted embryos with two-cell embryonic cell nuclear transfer. Mol. Reprod. Dev. 2004, 68, 313-318.

11. Popova, E; Bader, M; Krivokharchenko, A. Full-term development of rat after transfer of nuclei from two-cell stage embryos. Biol. Reprod. 2006, 75, 524-530.

12. Hayes, E.; Galea, S.; Verkuylen, A.; Pera, M.; Morrison, J.; Lacham-Kaplan, O.; Trounson, A. Nuclear transfer of adult and genetically modified fetal cells of the rat. Physiol. Genomics. 2001, 5, 193-204.

13. Iannaccone, P.; Taborn, G.; Garton, R. Preimplantation and postimplantation development of rat embryos cloned with cumulus cells and fibroblasts. Zygote 2001, 9, 135-143.

14. Kato, M.; Hirabayashi, M.; Aoto, T.; Ito, K.; Ueda, M.; Hochi, S. Strontium-induced activation regimen for rat oocytes in somatic cell nuclear transplantation. J. Reprod. Dev. 2001, 47, 407-413.

15. Jiang, J.Y.; Mizuno, S.; Mizutani, E.; Miyoshi, K.; Kimura, N.; Sasada, H.; Sato, E. Nuclear transfer in rats using an established embryonic cell line and cumulus cells. J. Reprod. Dev. 2002, $48,505-511$.

16. Hirabayashi, M.; Kato, M.; Ishikawa, A.; Hochi, S. Factors influencing chromosome condensation and development of cloned rat embryos. Cloning Stem Cells 2003, 5, 35-42.

17. Zhou, Q.; Renard, J.P.; Le Friec, G.; Brochard, V.; Beaujean, N.; Cherifi, Y.; Fraichard, A.; Cozzi, J. Generation of fertile cloned rats by regulation oocyte activation. Science 2003, 302, 1179.

18. Tomioka, I.; Mizutani, E.; Yoshida, T.; Sugawara, A.; Inai, K.; Sasada, H.; Sato, E. Spindle formation and microtubule organization during first division in reconstructed rat embryos produced by somatic cell nuclear transfer. J. Reprod. Dev. 2007, 53, 835-842. 
19. Yoo, J.G.; Demers, S.P.; Lian, L.; Smith, L.C. Developmental arrest and cytoskeletal anomalies of rat embryos reconstructed by somatic cell nuclear transfer. Cloning Stem Cells 2007, 9, 382393.

20. Popova, E.; Bader, M.; Krivokharchenko, A. Efficient production of nuclear transferred rat embryos by modified methods of reconstruction. Mol. Reprod. Dev. 2009, 76, 208-216.

21. Hogan, B.; Costantini, F.; Lacy, E. Manipulating the Mouse Embryo: A laboratory Manual; Cold Spring Harbor: New York, NY, USA, 1986; p. 332.

22. Krivokharchenko, A.; Popova, E.; Zaitseva, I.; Vilianovich, L.; Ganten, D.; Bader, M. Development of parthenogenetic rat embryos. Biol. Reprod. 2003, 68, 829-836.

23. Kishi, J.; Noda, Y.; Narimoto, K.; Umaoka, Y.; Mori, T. Block to development in cultured rat 1cell embryos is overcome using medium HECM-1. Hum. Reprod. 1991, 6, 1445-1448.

24. Ouhibi, N.; Warren, J.; English, J.; Sullivan, N. Culture system for the development of the preimplantation rat embryo. Theriogenology 1994, 41, 535-551.

25. Matsumoto, H.; Sugawara, S. Development of rat embryos at the 1- and 2-cell stage in modified HECM1 medium after exposure to a medium that contained phosphate. J. Reprod. Dev. 1995, 41, 263-269.

26. Miyoshi, K.; Funahashi, H.; Okuda, K.; Niwa, K. Development of rat one-cell embryos in a chemically defined medium: Effects of glucose, phosphate and osmolarity. J. Reprod. Fertil. 1994, 100, 21-26

27. Miyoshi, K.; Kono, T.; Niwa, K. Stage-dependent development of rat 1-cell embryos in a chemically defined medium after fertilization in vivo and in vitro. Biol. Reprod. 1997, 56, 180-185.

28. Paria, B.C.; Dey, S.K. Preimplantation embryo development in vitro: cooperative interactions among embryos and role of growth factors. Proc. Natl. Acad. Sci. 1990, 87, 4756-4760.

29. Lane, M.; Gardner, D.K. Effect of incubation volume and embryo density on the development and viability of mouse embryos in vitro. Hum. Reprod. 1992, 7, 558-562.

30. Krivokharchenko, A.S.; Vil'ianovich, L.I.; Tatarinova, L.V.; Riabykh, V.P. The development of mouse embryos in vitro in a protein-free medium depending on the numbers of embryos in a microvolume of the medium. Ontogenez 1993, 24, 53-60.

31. Bavister, B.D. Culture of preimplantation embryos: facts and artifacts. Hum. Reprod. Update 1995, 1, 91-148.

32. Krivokharchenko, A.; Galat, V.; Ganten, D.; Bader, M. In vitro formation of tetraploid rat blastocysts after fusion of two-cell embryos. Mol. Reprod. Dev. 2002, 61, 460-465.

33. Popova, E.; Krivokharchenko, A.; Ganten, D.; Bader, M. Efficiency of transgenic rat production is independent of transgene-construct and overnight embryo culture. Theriogenology 2004, 61, 1441-1453.

34. Popova, E; Bader, M; Krivokharchenko, A. Effects of electric field on early preimplantation development in vitro in mice and rats. Hum. Reprod. 2011, 26, 662-670.

35. Vajta, G.; Peura, T.T.; Holm, P.; Páldi, A.; Greve, T.; Trounson, A.O.; Callesen, H. New method for culture of zona-included or zona-free embryos: the Well of the Well (WOW) system. Mol. Reprod. Dev. 2000, 55, 256-264. 
36. Peura, T.T. Improved in vitro development rates of sheep somatic nuclear transfer embryos by using a reverse-order zona-free cloning method. Cloning Stem Cells. 2003, 5, 13-24.

37. Skrzyszowska, M.; Smorag, Z. The effective culture method of zona-free rabbit 1-, 2- and 4-cell embryos. Theriogenology 1994, 42, 159-164.

38. Vajta, G.; Korösi, T.; Du, Y.; Nakata, K.; Ieda, S.; Kuwayama, M.; Nagy, Z.P. The Well-of-theWell system: an efficient approach to improve embryo development. Reprod. Biomed. Online 2008, 17, 73-81.

39. Hashimoto, S.; Minami, N.; Takakura, R.; Yamada, M.; Imai, H.; Kashima, N. Low oxygen tension during in vitro maturation is beneficial for supporting the subsequent development of bovine cumulus-oocyte complexes. Mol. Reprod. Dev. 2000, 57, 353-360.

40. Bavister B. Oxygen concentration and preimplantation development. Reprod. Biomed. Online 2004, 9, 484-486.

41. Orsi, N.M.; Leese, H.J. Protection against reactive oxygen species during mouse preimplantation embryo development: role of EDTA, oxygen tension, catalase, superoxide dismutase and pyruvate. Mol. Reprod. Dev. 2001, 59, 44-53.

42. Rinaudo, P.F.; Giritharan, G.; Talbi, S.; Dobson, A.T.; Schultz, R.M. Effects of oxygen tension on gene expression in preimplantation mouse embryos. Fertil Steril. 2006, 86, 1252-1265.

43. Kito, S.; Kaneko, Y.; Yano, H.; Tateno, S.; Ohta, Y. Developmental responses of 2-cell embryos to oxygen tension and bovine serum albumin in Wistar rats. Exp. Anim. 2008, 57, 123-128.

44. Popova, E.; Krivokharchenko, A.; Ganten, D.; Bader, M. Comparison between PMSG- and FSH-induced superovulation for the generation of transgenic rats. Mol. Reprod. Dev. 2002, 63, 177-182.

45. Tarkowski, A.K. An air-drying method for chromosome preparations from mouse eggs. Cytogenetics 1966, 5, 394-400.

(C) 2011 by the authors; licensee MDPI, Basel, Switzerland. This article is an open access article distributed under the terms and conditions of the Creative Commons Attribution license (http://creativecommons.org/licenses/by/3.0/). 